\title{
The effect of resistance exercise on fitness, blood pressure, and blood lipid of hypertensive middle-aged men
}

\author{
Kyu-Sik Shim, Jong-Won Kim* \\ Department of Physical Education, Busan National University of Education, Busan, Korea
}

The purpose of this study is to investigate the effect of resistance exercise on fitness, blood pressure, and blood lipid of hypertensive middle-aged men. To achieve the goal of the study, a total of 23 subjects were selected. Among them, 14 subjects who exercised regularly were selected as the exercise group, while the remaining 9 subjects were selected as the control group. In terms of data processing, the IBM SPSS Statistics ver. 21.0 software was used to calculate the mean and standard deviation. Regarding the verification of difference on the change of means between the groups, analysis of covariance was used for statistical process. As a result, significant differences were found in cardiovascular endurance, muscle endurance, flexibility, and triglyceride. These results indicate that the resistance exercise only had slight effect on hypertensive middle-aged men.

Keywords: Blood lipid, Blood pressure, Fitness, Hypertension, Resistance exercise, Middle-aged men

\section{INTRODUCTION}

As the middle age is the period in which physiological function gradually starts to decrease and chronic diseases increase, the health of a person at this age thus becomes an important issue not only from the personal aspect but also from the social aspect.

After the age of 50 - the transition into senescence-mortality caused by cerebrovascular and cardiovascular diseases rapidly increases. Therefore, prevention is of utmost importance, and it becomes necessary to systematically manage one's blood lipid, high blood pressure, smoking, diabetes, obesity, lack of exercise, past medical history, etc. (Burke et al., 2001).

Recently, the incidence of hypertension has increased in Korea due to the Westernized eating habit of the people and their lack of exercise. Hypertension, one of the chronic degenerative diseases, is not just among the most common cardiovascular diseases but is also among all types of human diseases that continue to threaten national health all over the world.

According to a study that estimated such data of the whole world, $54 \%$ of stroke, $47 \%$ of ischemic heart diseases, $75 \%$ of hy- pertensive diseases, and $25 \%$ of other cardiovascular disease are caused by hypertension (Lawes et al., 2008).

In addition, the study conducted by Sipahi et al. (2006) reported that as blood pressure increased, the prevalence of coronary artery disease and stroke also gradually increased. Moreover, there were more possibilities that these diseases would be metastasized into hypertension in the future unless one made changes to his or her life habit to decrease blood pressure (Liszka et al., 2005).

In the guideline to treat hypertension, it is stated that improvement of eating habit—such as low salt diet—and life habit—such as regular exercise prior to drug therapy—need to be conducted first (Chobanian et al., 2003). In particular, it was described that regular exercise can lower the blood pressure up to a systolic blood pressure of $20 \mathrm{mmHg}$ and a diastolic blood pressure of $11 \mathrm{mmHg}$ (Pescatello et al., 2004). In addition, regular exercise was suggested as an effective treatment method in that it could decrease or discontinue drug dosage and thus reduce cardiovascular risk factors (Liszka et al., 2005; Poehlman et al., 2000). Such statement only serves to emphasize the importance of exercise.

According to Williams (2001), it has been reported that regular
${ }^{*}$ Corresponding author: Jong-Won Kim (iD http://orcid.org/0000-0001-6576-9097 Department of Physical Education, Busan National University of Education, 24 Gyodae-ro, Yeonje-gu, Busan 47503, Korea

Tel: +82-51-500-7254, Fax: +82-51-500-7254, E-mail: 1004kjw@bnue.ac.kr Received: January 6, 2017 / Accepted: February 4, 2017
This is an Open Access article distributed under the terms of the Creative Commons Attribution Non-Commercial License (http://creativecommons.org/licenses/by-nc/4.0/) which permits unrestricted non-commercial use, distribution, and reproduction in any medium, provided the original work is properly cited. 
exercise is important, but fitness level itself is closely related to cardiovascular diseases, including hypertension, and that fitness level should be classified as an independent risk factor that is separate from exercise.

As such, health promotion activities through exercise can be said to be an essential process to improve the quality of life of hypertensive patients. Recently, resistance exercise has been recommended as an exercise method for hypertensive patients (Pescatello et al., 2004), and it has now also been revealed that resistance exercise is effective in not only musculoskeletal diseases but also in the prevention and treatment of blood pressure. Moreover, it can help decrease risk factors of cardiovascular diseases as the amount of muscle increases due to muscle strengthening exercise (Braith and Stewart, 2006). Therefore, to maintain a healthy life, it is important to increase the amount of simple physical activities as well exercise systematically with a specific purpose of increasing the fitness level (Batt et al., 2013).

However, many researchers attempt to conduct studies related to hypertensive patients using methods with multiple perspectives. Nevertheless, most studies did investigate on the effectiveness of aerobic exercise (Cornelissen and Fagard, 2005; Tanaka et al., 2000; Edwards and Lang, 2005). Moreover, there are not many studies that focus on investigating the effect of fitness level and resistance exercise.

Taking all these into consideration, the purpose of this study is to investigate the effects of regular participation in resistance exercise on fitness, blood pressure, and blood lipid of middle-aged men.

Table 1. Physical characteristics of subjects in each group

\begin{tabular}{lcc}
\hline \multirow{2}{*}{ Variable } & \multicolumn{2}{c}{ Group } \\
\cline { 2 - 3 } & Exercise $(\mathrm{n}=14)$ & Control $(\mathrm{n}=9)$ \\
\hline Age $(\mathrm{yr})$ & $44.07 \pm 7.72$ & $45.67 \pm 6.78$ \\
Height $(\mathrm{cm})$ & $176.93 \pm 9.11$ & $170.56 \pm 4.97$ \\
Weight $(\mathrm{kg})$ & $85.41 \pm 15.55$ & $74.63 \pm 10.54$ \\
Body mass index $\left(\mathrm{kg} / \mathrm{m}^{2}\right)$ & $26.93 \pm 2.95$ & $25.68 \pm 3.55$ \\
\hline
\end{tabular}

Values are presented as mean \pm standard \pm deviation.

\section{MATERIALS AND METHODS}

\section{Subjects}

This study conducted a health diagnosis among middle-aged men living in Yangsan-gun and selected a total of 23 middle-aged men. They were subsequently grouped into two, Exercise $(n=14)$ and control ( $n=9)$ groups, who were found to have hypertension. Consent forms from the selected subjects were subsequently submitted. The physical characteristics of the subjects are described in Table 1.

\section{Instrument of measurement}

The items and instruments of the measurement are described in Table 2.

\section{Measurement item and methods}

Regarding physical fitness assessment for this study, muscular strength (strength of grasp), muscular endurance (curl ups), flexibility (sit and reach), and cardiovascular endurance (20-m shuttle run) — which were also conducted in the National Physical Fitness Survey - were conducted twice before and after the exercise. Regarding blood pressure, systolic and diastolic blood pressures were measured using a mercury sphygmomanometer after stabilization. With regard to the blood lipid, total cholesterol (TC), triglycerides (TG), high-density lipoprotein-cholesterol (HDL-C), low-density lipoprotein-cholesterol (LDL-C), were analyzed through blood collection.

\section{Exercise program}

The exercise period for this study was 15 weeks, and frequency was set to twice a week. The exercise time was set from 40 to 50 min. The program was composed of warm-up, main exercise, and cooldown, wherein exercise intensity was adjusted according to the principle of gradual overload. The detailed exercise program is described in the table below (Table 3).

Table 2. Items and instruments of the measurement

\begin{tabular}{lll}
\hline Instrument & \multicolumn{1}{c}{ Model/country of manufacture } & Measurement item \\
\hline Body composition & InBody 430 Biospace/Korea & Weight, body mass index \\
Muscular strength & Digital dynamometer (TKK-5401)/Japan & Grip strength \\
Muscular endurance & Mat, stopwatch (HS-3V)/China & Partial curl up \\
Flexibility & TKK 5103/Japan & Sit and reach \\
Cardiovascular endurance & Audio, CD recording paper/Canada & 20-m shuttle run \\
Blood pressure & HICO/Japan & Systolic blood pressure/diastolic blood pressure \\
\hline
\end{tabular}




\section{Data processing}

IBM SPSS Statistics ver. 21.0 (IBM Co., Armonk, NY, USA) was used to calculate the mean and the standard deviation of the measured items, and analysis of covariance was conducted to verify the difference between variables. Statistical significance $(\alpha)$ was set to 0.05 .

\section{RESULTS}

When examining the verification of differences among cardiovascular endurance, muscular endurance, and flexibility, statisti- cally significant differences $(P<0.01, P<0.01$, and $P<0.05)$ (Table 4 ) were found among the groups. In the result regarding difference in muscular strength, no statistically significant difference was found.

\section{Effects on blood pressure factors}

According to the result of the differences in systolic and diastolic blood pressures, no statistically significant differences were observed in both results (Table 5).

When analyzing the differences of TG, statistically significant differences between groups $(P<0.05)$ were found. On the other

Table 3. Interval exercise for 15 weeks

\begin{tabular}{|c|c|c|c|c|c|}
\hline Term (wk) & & Contents & Intensity & Time & Frequency \\
\hline & Warm up & Dynamic \& active stretching & 40\% HRR (7 RPE) & 5-10 min & 2 times/wk (15 W) \\
\hline $1-6$ & Body weight exercise & $\begin{array}{l}\text { Walking squat \& lunge, Multiple step up, Bridge, Superman, Crunch, Push up hold, } \\
\text { Shoulder touch, Jumping pull up }\end{array}$ & $\begin{array}{l}50 \%-60 \% \text { HRR } \\
\text { (9-11 RPE) }\end{array}$ & $30 \mathrm{~min}$ & 2 times/wk (15 W) \\
\hline $7-12$ & Body weight exercise & $\begin{array}{l}\text { Walking squat \& lunge, Multiple step up, Bridge, Superman, Crunch, Push up hold, } \\
\text { Shoulder touch, Jumping pull up }\end{array}$ & $\begin{array}{l}60 \%-70 \% \text { HRR } \\
\text { (11-13 RPE) }\end{array}$ & $30 \mathrm{~min}$ & 2 times/wk (15W) \\
\hline \multirow[t]{2}{*}{$12-15$} & Body weight exercise & $\begin{array}{l}\text { Walking squat \& lunge, Multiple step up, Bridge, Superman, Crunch, Push up hold, } \\
\text { Shoulder touch, Jumping pull up }\end{array}$ & $\begin{array}{l}\text { 70\%-80\% HRR } \\
\text { (13-15 RPE) }\end{array}$ & $30 \mathrm{~min}$ & 2 times/wk (15W) \\
\hline & Cool down & Passive \& floor stretching & $40 \%$ HRR (7 RPE) & 5-10 min & 2 times/wk (15W) \\
\hline
\end{tabular}

HRR, heart rate reserve; RPE, rating of perceived exertion.

Table 4. Analysis of the result of the effects of resistance exercise on fitness factors

\begin{tabular}{|c|c|c|c|c|c|c|}
\hline Source & Mean \pm SD & Sum of squares & $d f$ & Mean square & $F$ & $R^{2}$ \\
\hline Cardiovascular endurance & & $5,305.132$ & 1 & $5,305.132$ & $63.357^{* * *}$ & \\
\hline Exercise group & $53.07 \pm 16.62$ & $1,135.052$ & 1 & $1,135.052$ & $13.555^{* *}$ & 0.142 \\
\hline Control group & $44.11 \pm 20.58$ & $1,135.052$ & 1 & $1,135.052$ & $13.555^{* *}$ & 0.142 \\
\hline Deviation & & $1,674.686$ & 20 & 83.734 & & \\
\hline Total & & $7,419.652$ & 22 & & & \\
\hline Muscular endurance & & 2,297.375 & 1 & $2,297.375$ & $279.697^{* * *}$ & \\
\hline Exercise group & $28.43 \pm 7.65$ & 69.780 & 1 & 69.780 & $8.495^{* *}$ & 0.929 \\
\hline Control group & $24.56 \pm 14.57$ & 69.780 & 1 & 69.780 & $8.495^{* *}$ & 0.929 \\
\hline Deviation & & 164.276 & 20 & 8.214 & & \\
\hline Total & & $2,543.826$ & 22 & & & \\
\hline Flexibility & & 905.484 & 1 & 905.484 & $159.032^{* * *}$ & \\
\hline Exercise group & $8.32 \pm 5.85$ & 43.570 & 1 & 43.570 & $7.652^{*}$ & 0.907 \\
\hline Control group & $2.22 \pm 8.46$ & 43.570 & 1 & 43.570 & $7.652^{*}$ & 0.907 \\
\hline Deviation & & 113.875 & 20 & 5.694 & & \\
\hline Total & & $1,223.152$ & 22 & & & \\
\hline Muscular strength & & $1,195.681$ & 1 & 1,195.681 & $80.947^{* * *}$ & \\
\hline Exercise group & $47.93 \pm 9.43$ & 6.634 & 1 & 6.634 & 0.449 & \\
\hline Control group & $41.98 \pm 6.45$ & 6.634 & 1 & 6.634 & 0.449 & \\
\hline Deviation & & 295.423 & 20 & 14.771 & & \\
\hline Total & & $1,685.100$ & 22 & & & \\
\hline
\end{tabular}

SD, standard deviation.

${ }^{*} P<0.05$. ${ }^{* *} P<0.01$. ${ }^{* *} P<0.001$. 
Table 5. Analysis result of the effects of resistance exercise on blood pressure factors

\begin{tabular}{|c|c|c|c|c|c|c|}
\hline Source & Mean $\pm S D$ & Sum of squares & $d f$ & Mean square & $F$ & $R^{2}$ \\
\hline SBP & & $1,300.299$ & 1 & $1,300.299$ & 6.474 & \\
\hline Exercise group & $147.21 \pm 17.99$ & 0.320 & 1 & 0.320 & 0.002 & 0.266 \\
\hline Control group & $141.89 \pm 11.77$ & 0.320 & 1 & 0.320 & 0.002 & 0.266 \\
\hline Deviation & & $4,016.948$ & 20 & 200.847 & & \\
\hline Total & & $5,472.609$ & 22 & & & \\
\hline DBP & & 134.260 & 1 & 134.260 & 0.696 & \\
\hline Exercise group & $89.64 \pm 16.02$ & 2.432 & 1 & 2.432 & 0.013 & 0.034 \\
\hline Control group & $89.56 \pm 9.02$ & 2.432 & 1 & 2.432 & 0.013 & 0.034 \\
\hline Deviation & & $3,857.176$ & 20 & 192.859 & & \\
\hline Total & & $3,991.478$ & 22 & & & \\
\hline
\end{tabular}

SD, standard deviation; SBP, systolic blood pressure; DBP, diastolic blood pressure.

Table 6. Analysis of the result of effects of resistance exercise on blood lipid factors

\begin{tabular}{|c|c|c|c|c|c|c|}
\hline Source & Mean $\pm S D$ & Sum of squares & $d f$ & Mean square & $F$ & $R^{2}$ \\
\hline $\mathrm{TC}$ & & $14,601.635$ & 1 & $14,601.635$ & $18.551^{* * *}$ & \\
\hline Exercise group & $190.71 \pm 37.80$ & 96.557 & 1 & 96.557 & 0.123 & 0.512 \\
\hline Control group & $171.89 \pm 38.35$ & 96.557 & 1 & 96.557 & 0.123 & 0.512 \\
\hline Deviation & & $15,742.111$ & 20 & 787.106 & & \\
\hline Total & & $32,285.217$ & 22 & & & \\
\hline TG & & 2,937.968 & 1 & 2,937.968 & 1.270 & \\
\hline Exercise group & $183.14 \pm 55.24$ & $11,055.750$ & 1 & $11,055.750$ & $4.779^{*}$ & 0.351 \\
\hline Control group & $119.67 \pm 34.51$ & $11,055.750$ & 1 & $11,055.750$ & $4.779 *$ & 0.351 \\
\hline Deviation & & $46,265.746$ & 20 & 2,313.287 & & \\
\hline Total & & $71,276.870$ & 22 & & & \\
\hline HDL-C & & 1,695.288 & 1 & 1,695.288 & 49.251 & \\
\hline Exercise group & $47.14 \pm 10.41$ & 45.752 & 1 & 45.752 & 1.329 & 0.718 \\
\hline Control group & $50.33 \pm 11.03$ & 45.752 & 1 & 45.752 & 1.329 & 0.718 \\
\hline Deviation & & 688.427 & 20 & 34.421 & & \\
\hline Total & & $2,439.478$ & 22 & & & \\
\hline LDL-C & & $14,998.487$ & 1 & $14,998.487$ & 17.966 & \\
\hline Exercise group & $112.79 \pm 43.72$ & 3.893 & 1 & 3.893 & 0.005 & 0.480 \\
\hline Control group & $104.11 \pm 29.24$ & 3.893 & 1 & 3.893 & 0.005 & 0.480 \\
\hline Deviation & & $16,696.759$ & 20 & 834.838 & & \\
\hline Total & & $32,107.478$ & 22 & & & \\
\hline
\end{tabular}

SD, standard deviation; TC, total cholesterol; TG, triglycerides; HDL-C, high-density lipoprotein-cholesterol; LDL-C, low-density lipoprotein-cholesterol.

${ }^{*} P<0.05$. ${ }^{* *} P<0.001$.

hand, regarding TC, HDL-C, and LDL-C, no statistically significant differences were found (Table 6).

\section{DISCUSSION}

This study was conducted to investigate whether resistance exercise had an effect on fitness, blood pressure, and blood lipid of hypertensive patients who did not receive drug treatment. As a result, cardiovascular endurance, muscular endurance, flexibility, and TG showed statistically significant influence. However, muscular strength, systolic blood pressure, diastolic blood pressure, TC, HDL-C, and LDL-C did not show statistically significant differences.

Thus, with the results found in this study as the basis, the following were discussed.

Hypertension is the main cause of atherosclerotic vascular change and reportedly increases the degree of death risk brought about by cardiovascular diseases. Most stage 1 hypertensive pa- 
tients do not receive antihypertensive agents when they are suffering from their hypertensive condition. As such, it is recommended that they do appropriate exercise for blood pressure control and nutritional management (Vasan et al., 2001).

Fitness is a physical ability required for daily life activities or to utilize one's motor skills. It is comprised of the following factors-cardiovascular endurance, muscular strength, muscular strength, flexibility, and body composition.

Cardiovascular endurance is the most important predictor in identifying signs of cardiovascular diseases. Santa-Clara et al. (2003) reported that resistance exercise increased cardiopulmonary functions and lowered the elasticity of the vessel wall or decreased the damage of the inner vessel wall to improve vascular functions, which was similar to the results of this study. In addition, to improve muscular endurance in general, it was reported that resistance exercise training, it was recommended that such exercises be repeated 12 times and more (Pauole et al., 2000). As repetitive resistance exercise conducted in this study was enough to improve muscular strength, it is inferred that such exercise had a significant effect on it.

On the other hand, no significant influence in muscular strength was found. This is because the load was gradually increased from a low intensity of 1 repetition maximum as the subjects were hypertensive patients. However, when taking into consideration that muscular strength had significant influence, it is believed that constant resistance exercise would have a positive effect on muscular strength.

Fagard (2001) also reported that persons with high blood pressure in resting condition had greatly decreased their weight because of exercise. The result of the current study showed that it did not have a significant effect on both systolic and diastolic blood pressures.

As endurance exercise training can lower the blood pressure in hypertensive patients as reported in Whelton et al. (2002), it is thought that the above result came out because the current study program was limited to resistance exercise.

Blood lipid components include TC, TG, HDL-C, LDL-C, etc., which are all critical factors to evaluate the degree of cardiovascular disease risk. Cholesterol imbalance is the greatest cause of hypertension (Ferrara et al., 2002).

Misra et al. (2008) had middle-aged women do resistance exercise three times a week and stated that significant decrease of TG was found, which was consistent with the current study. However, TC, HDL-C, and LDL-C did not show significant differences. Durstine et al. (2002) reported that there was no general signifi- cant decrease with only exercise training. Moreover, it was not affected by the exercise period. However, Katzmarzyk et al. (2001) reported that regular and continuous resistance exercise at a particular intensity and more for a long time would decrease TC. It is inferred that increasing the frequency and constantly exercising would be more effective.

When the above results are taken together, Thompson et al. (2001) stated that blood pressure decrease due to training is an accumulative phenomenon from repetitive hypotensive phenomena found after one-time exercise, thus emphasizing the importance of continuous exercise in hypertensive patients.

However, resistance exercise—including interval exercise—had an effect on fitness improvement, but the blood pressure increase was high at exercise in the middle age. Therefore, personal health conditions and fitness level should be taken into consideration when implementing an exercise program.

\section{CONFLICT OF INTEREST}

No potential conflict of interest relevant to this article was reported.

\section{REFERENCES}

Batt ME, Tanji J, Börjesson M. Exercise at 65 and beyond. Sports Med 2013;43:525-530.

Braith RW, Stewart KJ. Resistance exercise training: its role in the prevention of cardiovascular disease. Circulation 2006;113:2642-2650.

Burke GL, Arnold AM, Bild DE, Cushman M, Fried LP, Newman A, Nunn C, Robbins J; CHS Collaborative Research Group. Factors associated with healthy aging: the cardiovascular health study. J Am Geriatr Soc 2001;49:254-262.

Chobanian AV, Bakris GL, Black HR, Cushman WC, Green LA, Izzo JL Jr, Jones DW, Materson BJ, Oparil S, Wright JT Jr, Roccella EJ, National Heart, Lung, and Blood Institute Joint National Committee on Prevention, Detection, Evaluation, and Treatment of High Blood Pressure; National High Blood Pressure Education Program Coordinating Committee. The seventh report of the joint national committee on prevention, detection, evaluation, and treatment of high blood pressure: the JNC7 report. JAMA 2003;289:2560-2572.

Cornelissen VA, Fagard RH. Effects of endurance training on blood pressure, blood pressure-regulating mechanisms, and cardiovascular risk factors. Hypertension 2005;46:667-675.

Durstine JL, Grandjean PW, Cox CA, Thompson PD. Lipids, lipoproteins, and exercise. J Cardiopulm Rehabil 2002;22:385-398. 
Edwards DG, Lang JT. Augmentation index and systolic load are lower in competitive endurance athletes. Am J Hypertens 2005;18(5 Pt 1):679683.

Fagard RH. Exercise characteristics and the blood pressure response to dynamic physical training. Med Sci Sports Exerc 2001;33(6 Suppl):S484-492.

Ferrara LA, Guida L, Iannuzzi R, Celentano A, Lionello F. Serum cholesterol affects blood pressure regulation. J Hum Hypertens 2002;16:337343.

Katzmarzyk PT, Pérusse L, Malina RM, Bergeron J, Després JP, Bouchard C. Stability of indicators of the metabolic syndrome from childhood and adolescence to young adulthood: the Québec Family Study. J Clin Epidemiol 2001;54:190-195.

Lawes CM, Vander Hoorn S, Rodgers A; International Society of Hypertension. Global burden of blood-pressure-related disease, 2001. Lancet 2008;371:1513-1518.

Liszka HA, Mainous AG 3rd, King DE, Everett CJ, Egan BM. Prehypertension and cardiovascular morbidity. Ann Fam Med 2005;3:294-299.

Misra A, Alappan NK, Vikram NK, Goel K, Gupta N, Mittal K, Bhatt S, Luthra K. Effect of supervised progressive resistance-exercise training protocol on insulin sensitivity, glycemia, lipids, and body composition in Asian Indians with type 2 diabetes. Diabetes Care 2008;31:12821287.

Pauole K, Madole K, Garhammer J, Lacourse M, Rozenek R. Reliability and validity of the T-test as a measure of agility leg power, and leg speed in college-aged men and women. J Strength Cond Res 2000;14: 443-450.

Pescatello LS, Franklin BA, Fagard R, Farquhar WB, Kelley GA, Ray CA; American College of Sports Medicine. American College of Sports
Medicine position stand. Exercise and hypertension. Med Sci Sports Exerc 2004;36:533-553.

Poehlman ET, Dvorak RV, DeNino WF, Brochu M, Ades PA. Effects of resistance training and endurance training on insulin sensitivity in nonobese, young women: a controlled randomized trial. J Clin Endocrinol Metab 2000;85:2463-2468.

Santa-Clara H, Fernhall B, Baptista F, Mendes M, Bettencourt Sardinha L. Effect of a one-year combined exercise training program on body composition in men with coronary artery disease. Metabolism 2003; 52:1413-1417.

Sipahi I, Tuzcu EM, Schoenhagen P, Wolski KE, Nicholls SJ, Balog C, Crowe TD, Nissen SE. Effects of normal, pre-hypertensive, and hypertensive blood pressure levels on progression of coronary atherosclerosis. J Am Coll Cardiol 2006;48:833-838.

Tanaka H, Dinenno FA, Monahan KD, Clevenger CM, DeSouza CA, Seals DR. Aging, habitual exercise, and dynamic arterial compliance. Circulation 2000;102:1270-1275.

Thompson PD, Crouse SF, Goodpaster B, Kelley D, Moyna N, Pescatello L. The acute versus the chronic response to exercise. Med Sci Sports Exerc 2001;33(6 Suppl):S438-445.

Vasan RS, Larson MG, Leip EP, Evans JC, O’Donnell CJ, Kannel WB, Levy D. Impact of high-normal blood pressure on the risk of cardiovascular disease. N Engl J Med 2001;345:1291-1297.

Whelton SP, Chin A, Xin X, He J. Effect of aerobic exercise on blood pressure: a meta-analysis of randomized, controlled trials. Ann Intern Med 2002;136:493-503.

Williams PT. Physical fitness and activity as separate heart disease risk factors: a meta-analysis. Med Sci Sports Exerc 2001;33:754-761. 